\title{
Language, Imagery and Ideology in Japanese Law and Administration
}

\author{
Richard Powell ${ }^{1}$ \\ Published online: 23 July 2019 \\ (c) Springer Nature B.V. 2019
}

Three decades ago a spate of studies (notably [3]) helped convince readers beyond Japan that its legal system was rather more culturally grounded than the technical and abstract domain or the last resort for conflict resolution that it had typically been made out to be in consensus-focused accounts. More recently, comparative investigations (such as [1]) have constructed dynamic and socially situated pictures of a legal system adapting to fundamental economic and political shifts. Other globallytargeted work is exploring the sociocultural dimension of Japanese justice through the ways in which it is depicted in the virtual world of video games, anime and manga (e.g. [2]). There nevertheless remains considerable scope for further treatments of the cultural and ideological dimensions of Japanese law in languages other than Japanese. Focusing on language and images, the articles in this collection step back from legal processes themselves in an attempt to situate Japanese law in the complex, diverse and politicised environment that surrounds it.

Just over 10 years have passed since the establishment of the Japan Association of Law and Language (JALL/Hōtogengo Gakkai 法之言語学会). In a speech at JALL's inauguration in December 2008, John Gibbons, former president of the International Association of Forensic Linguists, offered several pointers on what Japan-related scholars might contribute to research on legal communication. Highlighting the challenge of ongoing top-down reforms aimed at making law more accessible, he emphasised the need to analyse legal lexis in light of the rapid inflow of new concepts; expose interpersonal and power dynamics in view of increased contact between lawyers and lay participants; and gauge the impact of modality shifts whereby legal professionals were turning from written texts toward orality and images. To gain insights into these and other areas Gibbons urged academics to build bridges with judges, prosecutors, lawyers and the police, while foreseeing a challenge for legal interpreters and translators in a society that could no longer pretend to be linguistically or culturally homogeneous.

Richard Powell

ricpowell@yahoo.com

1 Nihon University, Tokyo, Japan 
This collection of ten articles contributed by 12 authors, many of them active members of JALL, aims to show something of the breadth of studies being carried out within a variety of academic paradigms at the intersections among language, ideology and justice. Encompassing legal interpreting, interpersonal dynamics, visual communication, differential understanding of legal lexis, and the legal and ideological packaging of cultural symbols, the writers engage with many of the issues raised by Gibbons.

JALL is not the only Japan-based body fostering research on law and language. Kikan Keiji Bengo, published by the Japan Federation of Bar Association, and Tsuyaku Kenkyu, the journal of the Japan Association of Interpretation Studies, have helped publicise work related to legal translation, while Shakai Gengo Gak$\mathrm{kai}$, an institution devoted to sociolinguistics, has addressed trademark disputes. Publications more specifically focused on law, including Hanzaishakaigaku Kenkyū (the Japanese Journal of Sociological Criminology), have covered issues involving linguistic or discursive analysis, such as case construction and stalking. However, since 2009 JALL has played a pivotal role in coordinating research across a range of fields, holding regional gathering two or three times a year in addition to its annual general meeting every December. It also publishes Hō to Gengo (法と言語), which mostly carries articles written in Japanese but welcomes contributions in English.

2009 was an important year for the Japanese justice system, and for academic research into its linguistic and ideological aspects, as it saw the launch of a system of lay judges (Saibanin Seido) to adjudicate criminal cases alongside professional judges. The new system was the centrepiece of a series of reforms brought in during the Heisei Era (1989-2019) to strengthen citizens' engagement with judicial practices and encourage more of them to enter the legal profession. Together they constitute modern Japanese law's third major reorganisation, following the adoption of a somewhat authoritarian version of European constitutionalism in the Meiji Era (1868-1912) and the introduction of more individualistic principles and adversarial procedures during the American occupation that split the Shōwa Era (1926-1989).

The Saibanin system has provided incentives to make legal processes more intelligible to lay citizens. Even before lay judge trials began, a number of simulations were run to investigate how non-lawyers understand legal procedures and how they respond to legal language. These encouraged linguists to turn their attention to issues such as empowered and disempowered discourse, gendered, socioeconomic and regional speech patterns, and the different understandings that professional and lay participants may have of lexis used in legal contexts.

Some of these simulations also entailed consideration of how trial participants are influenced by the presence of court interpreters. Interpreting has been an increasingly prominent feature of the Japanese courts because of the steady growth of residents who do not have Japanese as a first language, and analysis of both semantic and pragmatic equivalence in translation has had to take account of differences between Japanese general and legal culture on the one hand and the cultural background of non-Japanese participants on the other. This work in turn has revitalised scrutiny of the particular demands and dangers of police interviewing, reflecting concern for the problems of Japanese suspects overseas as well as for non-Japanese suspects in Japan. As of yet, lay judges are not used in Japanese civil cases, but 
greater awareness of the role of language in criminal law may encourage a more sociological and sociolinguistic turn in areas such as intellectual property and contract law.

The verdict is still out on whether Japan's current legal reforms are stimulating lay interest in the judicial system in the way envisaged, but from an academic perspective it is clear that lawyers and law academics have enhanced their understanding of the importance of language and discourse in the justice system, and this has formed the basis of a range of collaborations with linguists, sociolinguists and psycholinguists. JALL itself is a good example of this collaborative environment as it includes jurists, practising lawyers and judges, interpreting and translation specialists, descriptive linguists, sociolinguists, forensic linguists, legal historians and legal anthropologists among its participants. That said, it seems it may be some time before the police take the value of forensic linguistics on board.

The ten articles in this Special Issue have been grouped into five pairs of studies addressing related topics from different perspectives. The first pair of articles look at the ideology of courtroom interpreting. Nakane and Mizuno explore the Japanese judiciary's stances on interpreting through an analysis of judgments in which translated testimony was at issue, and examine court guidelines and media reports on interpreting. They conclude that judges frequently underplay the importance and implications of language difference in both trials and pre-trial investigations, possibly because oral processes in Japan's civil law-based court system have carried less weight than documentary investigation, and they express the hope that the use of lay judges and the introduction of mandatory recording of suspect interviews will raise awareness and standards. Meanwhile Shudo focuses on one specific difficulty for legal interpreters: apologies. Analysing data from a 2009 case in which a defence appeal on the grounds of interpreting mistakes was rejected, she highlights the problem of non-equivalence across languages. These may be significant even in apparently straightforward phrases such as "I felt bad", which might or might not contain an expression of apology in some languages and thereby have legal implications when evaluating the guilt or remorse of a defendant. Shudo also calls for interpreters to be given more opportunity to enhance their understanding of pragmatic issues, and for judges and attorneys to raise their awareness of the possibility of errors in the translations they depend on.

The second two articles take a visual turn in addressing the impact of body language and spatial issues in legal communication. Taira and Itagaki tackle some general questions arising from how people without hearing impairment evaluate the facial and bodily expressions employed by the hearing impaired and by signing interpreters. They then consider how these evaluations might influence trials involving hearing-impaired defendants or witnesses, especially where lay-judges are present. In particular they focus on visual language that may incorrectly be conflated with the gestures of hearing people when in fact they perform specific communicative functions among the non-hearing, and they warn of possible legal implications if uninformed assumptions are made about visual information. Ibusuki then takes up the impact of the video recording of police interviews, emphasising the risks of assuming that cameras do not lie. Comparing evidence from the United States, Sweden and elsewhere with findings from Japan, he argues that 
inevitable visual choices such as camera angles, the positioning of participants and exclusion of some of them from the frame, and the editing of lengthy videos into excerpts submitted in evidence, all conspire not merely to disadvantage suspects but actually to reinforce bias against them because of the belief on the part of many judges, both professional and lay, that visual recording is impartial. Despite the promotion of mandatory video recording by the Japanese Federation of Bar Associations he recommends controls over its use in order to avoid conveying the dangerous "illusion of transparency".

The next two articles explore other aspects of perceptual difference between insiders and outsiders, the first focusing on how the public, as well as legal professionals, treat the visual and linguistic components of trademarks, and the second addressing gaps between lay and lawyer understanding of terms used in litigation. Okawara applies updated linguistic analysis to a pair of trademark cases that arose over two decades ago, one involving a Japanese whisky maker sued by a Scottish distiller for using a name and logo the plaintiff claimed would confuse consumers, and the other involving a bar in Tokyo sued by French fashion house Chanel for using its name in signage. Noting how local courts sided with the defendant in the first case but with the plaintiff in the second, and concluding that contemporary social perceptions may play a role in apparently technical decisions, she highlights the relevance of orthographical choice in trademark cases, a component bridging linguistic and non-linguistic communication that is particularly relevant to languages like Japanese that employ several different scripts in combination. Okawara and Nishiguchi then investigate differential understanding of terms used in civil law. Comparing a judge's benchmark definitions with the interpretations of lay subjects, they argue that potential confusion may be particularly significant when lay people believe they understand terms without knowing how they are used in law, and they recommend more emphasis upon general legal education in order to close perceptual gaps.

The following pair of articles look at depictions of law in Japanese popular culture. Powell and Kumaki delve into the vast genre of manga on law and justice, focusing on a comic series about a kōban, or community police box. Seeing the manga medium as ideally suited to the combination of education with entertainment, and the police box as a halfway house between the formality and remoteness of the legal system and the more messy but familiar world of community policing, they review the history, architecture and symbolism of kōban in the real world before analysing how their chosen comic series employs a range of visual, linguistic, dramatic and narrative devices to construct a humorously anarchic yet somehow conservative image of social control. Wolff focuses on television, identifying a shift from the serious dramas typical of the 1990s to the more comic dramadies and infotainment that have dominated the medium's presentation of legal issues since the turn of the century. Linking the semiotics of humour to more broadly-based sociolegal and socio-semiotic studies, he argues that this televisual trajectory reflects Japanese society's heightened interest in the law in line with 21 st-century reforms in the legal system itself, while finding in the details of popular productions an enduring social sense that legalistic conflict resolution is still something incongruous to ordinary citizens' lives. 
The final two articles take an historical tack. Powell views the Japanese occupation of Singapore during World War II through the lens of Shonan Shimbun, an English-medium newspaper that reported not only on military and political events but also on day-to-day administration, law and order, and socioeconomic life. Its heavily censored texts and carefully selected images convey something of the efforts of the authorities to construct an ideological recolonisation of the island, and despite the editors' need to fall back on the language of the enemy, the newspaper shows how Japanese was also employed symbolically and visually alongside English and Malay to engineer cultural change. The issue is rounded off by Horie and CraneMikołajczyk's treatment of the cultural, linguistic and legal structures within which Japan's most important foodstuff has been represented socially and regulated administratively. After reviewing geographically and historically rooted customs surrounding rice and noting its current importance as an international symbol of Japan, they examine its place in national education and its intimate connection with the Japanese language, before going on to show how a complex of legal measures has evolved to regulate its production, distribution and quality.

Richard Powell, Tokyo, July, 2019.

\section{References}

1. Halpérin, Jean-Louis, and Naoki Kanayama. 2009. Droit japonais et droit français au miroir de la modernité. Paris: Dalloz.

2. Pearson, Ashley, Thomas Giddens, and Kieran Tranter (eds.). 2018. Law and Justice in Japanese Popular Culture. Abingdon: Routledge.

3. Upham, Frank K. 1989. Law and Social Change in Postwar Japan. Cambridge MA: Harvard University Press.

Publisher's Note Springer Nature remains neutral with regard to jurisdictional claims in published maps and institutional affiliations. 